\title{
Route effect on the perception of public transport services quality
}

\author{
Jorge Chica-Olmo \\ Quantitative methods for Economy and Business, University of Granada, Spain \\ Héctor Gachs-Sánchez \\ Managing director, Metropolitan Transportation Consortium area of Granada, Spain \\ Carmen Lizarraga \\ Applied Economics, University of Granada, Spain
}

\begin{abstract}
User satisfaction sets a basic example for public service quality, especially those considered as basic necessities. The quality in transport service related to conceptualization and measurement, as a decisive demand key, presents challenges for both economic and mobility policies.
\end{abstract}

Several operator companies are involved in the transport sector. Therefore this report aims to design a model of overall satisfaction based on the level of satisfaction with a specific set of factors, considering individual characteristics of users and the differential effect of different bus lines.

The current presentation has applied a combined method, using Nonlinear Principal Component Analysis (NLPCA) and a Logit Multilevel Model (LMLM) in two-steps.

\section{Introduction and literature review}

City dwellers are required to change their usual behaviour in order to create a new model of mobility and to use more sustainable ways when travelling, especially within metropolitan areas (Miralles, 2002; Lizárraga, 2006). As for public transport, this change must be relevant and will not be achieved only by improving the efficiency of vehicles design and traffic management. It also demands changes in the way transport is considered and how solutions are identified and evaluated (Litman, 2003).

The aim of this study is to provide a design model for components which define the perceived quality. As a case study, we used a satisfaction survey of the Metropolitan Transportation Consortium area of Granada in 2013. We should note that the interurban transport service is heterogeneous because it is managed by several operators with different lines or routes which provide service to different nearby towns. 
Measurement and conceptualization of public transport service quality is one of the most important challenges of economic analysis and mobility policies, given the importance of the results for both companies that offer these services and administrations (Román, Martín and Espino, 2014). Quality of service as well as transport fares, personal disposable income and vehicle ownership are considered essential factors which establish such demand (Paulley, Balcombe, Mackett, Titheridge, Preston, Wardman, Shires and White, 2006). Public policies aimed to encourage the use of public transport as an active tool to reduce traffic congestion and pollution must create a more attractive image and also, directed to the market and make it competitive compared to private vehicles (Beirão and Cabral, 2007: 478; dell’Ollio, Ibeas and Cecín, 2010: 388).

The study of public transport quality is part of services quality, an ambiguous concept and at the crossroad of a wide range of attributes (Grönroos, 1984; Parasuraman, Zeithaml and Berry, 1985; Hensher, Stopher and Bullock, 2003; Paulley et al., 2006; Beirão y Cabral, 2007; de Oña, de Oña, Eboli and Mazzulla, 2016). Thus, this opens up interesting fieldwork based research with practical implications for transport suppliers and authorities.

The concept and method of measuring quality have evolved since marketing began to address goods and services with a different approach. In this second area of research, Grönroos (1984) and Parasuraman et al. (1985) designed their respective quality models. In both models, the key is the correlation between expected performance and the subjective perception of the product. Such an approach clearly identifies three characteristics of the service which has been considered in our presentation: the intangibility of some service components; material and temporal heterogeneity in the delivery and reception of the service; service production and consumption are inseparable (Parasuraman et al., 1985: 42).

Unlike the evaluation of quality of durable goods, the fact that the service, the displacement of a person between two points in a public transport vehicle, is provided, received and consumed immediately and simultaneously with others users (Grönroos, 1984: 39) implies that close attention should be given to the process of providing and receiving service (Parasuraman et al., 1985: 42).

Public service delivery and receipt are not uniform; they vary from one day to another, from one operating company to another, from one route to another and even from one vehicle to another. Heterogeneity arises from transport system organization and diversity in the performance of each operating company, due to material endowment (Grönroos, 1984) and to the attitude and competence of its staff. All these peculiar characteristics of the transport sector make the complete standardization of services impossible.

The functional quality dimension takes into account consumer service satisfaction, this being understood as the process by which technical components are transferred to the public as a substantial feature. However, services are produced in interaction with consumers; 
consequently the technical dimension of quality does not by itself account for the perception of users. Public transport may be considered as a "high contact service" (Parasuraman et al., 1985: 43) in which the relationships between users and staff are very frequent and continuous. Both dimensions "what is obtained by a service user" and "how it is obtained", are consumed and perceived simultaneously but differently according to each individual. The perceived quality of the service arises from comparing the perceived service combination of functional and technical dimensions- with the expected service (Grönroos, 1984: 39). Grönroos includes corporate image, the perception consumers have of the company, as the third dimension of his quality model.

\section{Methodology}

Level of overall satisfaction is an added measure of how to perceive satisfaction concerning different aspects of the transport system. Global added satisfaction, which will be called "quality", is explained by satisfaction of a specific set of features. Satisfaction with respect to specific features of the transportation system may be called "specific satisfactions" (del Castillo and Benitez, 2013). Specific satisfactions can be measured by ordinal categorical variables. The level of specific satisfaction is an example of a phenomenon which cannot be objectively measured, although it can be evaluated using ordinal variables (Ferrari, Pagani and Fiorio, 2011).

Different methods have been used in order to study public service level of satisfaction. A review of such methods can be found in Ferrari and Manzi (2014). According to the authors, the most used methods are logit, probit and lineal regression. Nevertheless, other methods such as Principal Components Analysis (PCA) have being used in order to build up synthetic measures of satisfaction for different services. The logit and probit models aim to explain service satisfaction, measured as a binary variable, from a set of explanatory variables. For instance, Jilke and Van de Walle (2013) evaluated the existence of claims in different public services according to a set of socio-economic factors; Fiorio, Florio and Perucca (2013) study satisfaction with public transportation using four sets of explicative variables (demographic, city-specific aggregate, travel and transportation variables).

Another used method is Multilevel Models (MLM). Borra and Chiavarini (2005) adjusts an ordered logit multilevel model with random intercept to explain quality of public transport in Rome, showing that quality not only depends on a set of fixed factors, but also on contextual indicators concerning demographic and environmental features of municipality in which citizens live. Besides, Ji and Gao (2010) used an ordered logit multilevel model to evaluate the satisfaction of public transport in Beijing. It was found that the number of bus stops, access to the main places of the city, as well as people's socio-economic attributes have significantly affected satisfaction of residents with public transportation. 
The current presentation has applied a combined method, using Nonlinear Principal Component Analysis (NLPCA) and a Logit Multilevel Model (LMLM) in two-steps. The aim is to explain the quality of service, given this as a binary variable, in function of a set of explanatory variables. Thus, as a first step, NLPCA has been used because the specific satisfaction variables are ordinal, categorical and these should not be used directly as explanatory variables in the regression model, being as the marginal effect is not the same for all values of these categorical variables. We were also interested in measuring users' satisfaction by reducing the observed multi-dimensional variables into a lower number of numeric variables. As a second step, we decided to use LMLM to model the binary nature of the dependent variable, depending on the effect that synthetic variables obtained with NLPCA and other visible variables have on overall satisfaction with the interurban transport service in the metropolitan area of Granada. In addition, it is intended to analyze the differential effect on travellers' perception of quality depending on the bus route used.

\subsection{Nonlinear Principal Component Analysis (NLPCA)}

Ferrari, Pagani and Fiorio (2011) used a mix of two methods in two-steps: Nonlinear Principal Component Analysis (NLPCA) and MLM. In the first step, they construct with NLPCA a synthetic indicator -dependent variable- of overall satisfaction based on four relevant public services: land line telephone, electricity supply, postal and rail services. In a second step, they use an MLM with random intercept to explain the synthetic indicator through a set of socio-economic variables (gender, age, income, etc.). In the MLM, not only these sets of socio-economic variables were considered, but also the presence of random effects caused by the variability between citizen and country of residence.

NLPCA or categorical PCA is an optimal scaling method which belongs to non-linear multivariate analysis techniques. The aim of this methodology is similar to the standard PCA. However, this allows scaling variables at different levels of measurement, recognizing nonlinear relationships among them. When it is used to synthesize information from a pack of numeric variables in a small set of components, standard PCA is a suitable method. However, when operating with mixed measurement levels (nominal, ordinal, and numeric variables) NLPCA is more appropriate (Ferrari and Manzi, 2014; Linting, Meulman, Groenen and van der Koojj, 2007). Gifi (1990) offers a comprehensive explanation of nonlinear multivariate methods based on optimal scaling. A didactic and compressive introduction of this method is shown in Linting et al. (2007).

Regarding the choice of the number of factors, components and dimensions there are several methods one can use (Jackson, 1993). One of the most used is based upon a large number of dimensions and subsequently reduced using the criterion of Kaiser-Guttman, whereby those dimensions whose eigenvalue is greater than the unit are retained. This enables each component to explain a higher variance percentage than the percentage explained by each original variable by itself. Furthermore, Cronbach's alpha can be used as a measure of 
reliability, so that the closer it is to its maximum value, 1 , the greater the reliability of the scale.

In NLPCA, orthogonal rotation may be applied in the same way as standard PCA (Linting et al., 2007). The aim of orthogonal rotation is to find a simple structure with a similar pattern of component loading but more easily discerned, without a change in the variance percentage explained by every one of the components. For instance, VARIMAX is a method to find an orthogonal rotation close to a simple structure (Bartholomew, Steele, Galbraith and Moustaki, 2008).

\subsection{Logit Multilevel Model (LMLM)}

MLM is also often referred to as mixed-effects model. These kinds of models allow us to understand how nesting individuals within groups can explain the change in data variance. In MLM, it can be considered that there is a fixed effects part that can be observed and that affects all individuals equally, and some unobserved with a random component which can be modelled.

In our model we assume that the respondents (level-1) taking different bus lines (level-2) are affected by idiosyncratic elements which are similar for each line due to different factors related to the technical management of the transport authority -itinerary; number and location of stops; schedules- and the actual performance of each operator-age, performance and vehicle maintenance; driver behaviour; number of travellers; etc-. Therefore, we consider that there is no independence between respondents who use the same bus line, even assuming that there is a base model or "baseline" for all individuals. In addition, we consider that there is a set of fixed effects affecting all individuals equally. As indicated, the mixed effects model allows taking into account, on the one hand, these fixed effects and, secondly, to assume that there are random effects due to the idiosyncratic factors of each traveller.

LMLM is a particular case of a Generalized Linear Mixed Model (GLMM). The difference between MLM and LMLM is that LMLM family distribution is binomial rather than Gaussian. To account for the binary structure of the dependent variable we will specify a two-level binary logit model with random intercept (Snijders, 2011). Let's consider that $Y_{i j}$ represents the individual response ( $1=$ good quality, $0=$ bad quality) within cluster $\mathrm{j}$ (bus line). In general, we will consider a linear predictor, $\eta$, as a combination of fixed, $X \beta$, and random effects, $Z \gamma$ :

$$
\eta=X \beta+Z \gamma
$$

For binary outcome, we use a logistic link function, $g(\square)$, which relates the outcome Y to the linear predictor $\eta$ : 


$$
\begin{aligned}
& g(\square)=\log \left(\frac{p_{i j}}{1-p_{i j}}\right)=\eta=X \beta+Z \gamma \\
& \text { where: } p_{i j}=\operatorname{Pr}\left(\mathrm{Y}_{i j}=1\right)
\end{aligned}
$$

In the case of a random intercept model $Z \gamma=\gamma_{0 j}$ with $\gamma_{0 j} \square N\left(0, \sigma_{0}^{2}\right)$.

A measure of the importance of random effects is the variance partition coefficient (VPC) or intra-class correlation coefficient (ICC), which is the proportion of the variance attributed to variation among individuals. The ICC is interpreted as the correlation between two randomly selected individuals in one cluster (Ferrari et al., 2011). For a LMLM with random intercept, the ICC is obtained (Goldstein, Browne and Rasbash, 2002):

$$
\rho=\frac{\sigma_{0}^{2}}{\sigma_{0}^{2}+\sigma_{\varepsilon}^{2}}
$$

where: $\sigma_{\varepsilon}^{2}=\pi^{2} / 3=3.29$, which is the variance for the standard logistic distribution.

An alternative to ICC, is the R-squared (Nakagawa and Schielzeth, 2010). We have used the Marginal-R-squared (R2m) which represents the variance explained by fixed factors and Conditional-R-squared (R2c) which represents the variance explained by fixed and random factors (Nakagawa and Schielzeth, 2013).

\section{Data}

The data used in this study comes from the satisfaction survey conducted in March 2013 by the Metropolitan Transportation Consortium area of Granada. Of the 1,720 surveys conducted, for this paper 1,140 valid records were taken.

The metropolitan area is made up by the city of Granada and some other 51 municipalities. It is an 861 square kilometres territory where nearly 600,000people lived in 2013 . The length of lines exceeds 805 kilometres covered by 105 interurban vehicles. Transport services are provided by 54 bus lines, all of them having the central city as their origin and destination, managed by sixteen operators, some of whom are part of business groups.

Satisfaction surveys are the most widely used technique for analyzing the quality of public transport services. However, qualitative techniques also have their place in academic research (Beirão and Cabral, 2007), most of the time as a complement to quantitative studies (dell' Olio et al, 2010; Roman et al, 2014.)

Sometimes these surveys question both users and non-users of the service (Fellesson and Friman, 2008). Survey respondents can express their stated preferences (dell' Olio, Ibeas and Cecín, 2011) from which it is possible to construct experimental prototypes founded on hypothetical behaviour that can be directly tested with the group of real and potential users 
(Kroes and Sheldon, 1988; Hensher et al.,2003; Paulley et al., 2006: 300; Asensio and Matas, 2008; Román et al., 2014).

The 2013 satisfaction survey of the Metropolitan Transportation Consortium interviewed 1,720 personal bus riders. The sample selection was random from fees from fifty-four bus lines and sixteen operators. It also takes into account age and gender quotas. The questionnaire is structured and organized in two sections, the first of which contains information about the service (place and time of the interview, operator name, line number, origin and destination of the trip), personal characteristics (gender, age group, possession of driving license and vehicle) and travel habits (rate of public transport use, reasons for travelling, frequency of use, type of ticket or transport card used, way of access to destination).

The second section will focus on how to collect users' opinions about transportation service. In order to do so, we used an eleven point scale ( 0 to 10$)$ to evaluate thirteen items: information, punctuality, safety on board, driver behaviour, vehicle cleanliness, room inside the vehicle, temperature, easy access to get on /off the vehicle, fares, speed, daily service frequency or number of daily services, proximity to bus-stops and schedules.

\begin{tabular}{|l|l|l|}
\hline \multirow{3}{*}{ Gender } & Female & $59.20 \%$ \\
\cline { 2 - 3 } & Male & $40.80 \%$ \\
\hline \multirow{4}{*}{ Age } & $18-30$ years & $44.00 \%$ \\
\cline { 2 - 3 } & $31-60$ years & $46.35 \%$ \\
\cline { 2 - 3 } Frequency of use & More than 61 years & $9.65 \%$ \\
\hline \multirow{5}{*}{ Ticket type } & Almost daily & $53.15 \%$ \\
\cline { 2 - 3 } & Frequent & $24.45 \%$ \\
\cline { 2 - 3 } & Occasional & $12.20 \%$ \\
\cline { 2 - 3 } & Sporadic & $10.20 \%$ \\
\hline \multirow{5}{*}{} & One-way ticket & $15.50 \%$ \\
\cline { 2 - 3 } & Consortium card & $76.70 \%$ \\
\cline { 2 - 3 } & Senior card (+65 years) & $7.70 \%$ \\
\cline { 2 - 3 } & Another & $0.10 \%$ \\
\hline
\end{tabular}

Table 1. Sample characteristics (2013)

Source: Metropolitan Transportation Consortium area of Granada

\section{Models and results}

The intention of this paper is to model the overall satisfaction of the public transport service from the level of satisfaction with a specific set of factors, taking into account individual characteristics of users and the differential effect of the use of each of various bus routes or lines. 
In our model, the dependent variable is a binary one, obtained from an ordinal variable that represents the overall quality of service measured on 5 levels (very bad, bad, normal, good and very good). The quality variable is set to 1 if the service is considered good or very good and 0 in the other answers. This type of transformation has been used in previous reports on satisfaction in public transport, such as Fiorio et al. (2013), who transmutes the four level individual satisfaction variables into a dichotomous variable.

A set of 13 ordinal variables were considered in order to explain the quality of service provided which measures satisfaction with the specific service. Besides, some other individual factors were also considered such as gender, age, the use one's own vehicle and frequency of use of bus users.

\subsection{Principal Components Analysis}

First of all, a NLPCA analysis was carried out by using CATPCA command (Categorical Principal Components Analysis) implemented in the statistical software SPSS (Meulman and Heiser, 2001). This methodology was applied to the 13 ordinal variables in order to obtain variables of continuous type to explain service quality.

The principal component structure obtained using varimax rotation, yielded 2 factors and extracted $68.912 \%$ of total variance (see Table 2). Factor 1 accounted for $55.98 \%$ of variance and had loading on 10 items. We would like to place especial emphasis to some of these 10 items, which are: temperature, room/space, punctuality and safety. Such factors can be characterized as "Comfort".

Factor 2 accounted for $12.93 \%$ of variance and had loading on 3 items. This factor can be characterized as "Services supply" since the significant variables are schedules, frequency and proximity of bus-stops. 


\begin{tabular}{|l|c|c|}
\hline & \multicolumn{2}{|c|}{ Component } \\
\hline & 1 & 2 \\
\hline Information & 0.748 & 0.196 \\
Punctuality & 0.815 & 0.248 \\
Safety & 0.812 & 0.269 \\
Behaviour & 0.731 & 0.205 \\
Cleanliness & 0.800 & 0.226 \\
Space & 0.832 & 0.183 \\
Temperature & 0.837 & 0.181 \\
Access-Getting on/off & 0.772 & 0.089 \\
Fares & 0.669 & 0.188 \\
Speed & 0.737 & 0.300 \\
Frequency & 0.172 & 0.908 \\
Proximity & 0.315 & 0.792 \\
Schedule & 0.196 & 0.915 \\
\hline
\end{tabular}

Table 2: Rotated components matrix

Extraction method: Nonlinear principal component analysis

Internal consistency of these factors was tested using Cronbach's alpha and found to be very adequate for Factor 1 (0.935). However, it is low for Factor 2 (0.438). The Global fit was very high for both factors (0.962).

Figure 1 shows the Comfort Factor effect on the quality of service for the fifty-four bus lines, for each of the sixteen operators (letter A to P). A different behaviour was found depending on the line used. This different behaviour has to do with different factors related to unobservable factors affecting each route and the specific operation of each company, the organization of the transport system, itinerary, schedules, performance and condition of the vehicle, degree of occupation, etc. Special consideration must be given to the comparison between bus and private vehicle performances. Many times, for the same route, private vehicle speed (as expected performance) differs substantially from the bus commercial speed (real service performance). In this regard, the ease and the price of parking favour public transport in terms of time spent and the total cost of displacement. The difference between times spent in a private vehicle and on a bus works for every bus user as a significant bench mark to build a meter of satisfaction with public transport.

Thus, the differential impact of commercial speed for each bus route, due to itineraries across dense built-up areas with nearer stops (L2 and L3) or routes where there are bus-lanes or non-stop road sections ( $\mathrm{J} 1$ and L6), imply staying more time in the vehicle or at the bus stop and consequently, greater exposure to conditions of pleasure or displeasure with the received service. 
Therefore, it would be appropriate to examine whether there are indeed random effects caused by these intangible factors.

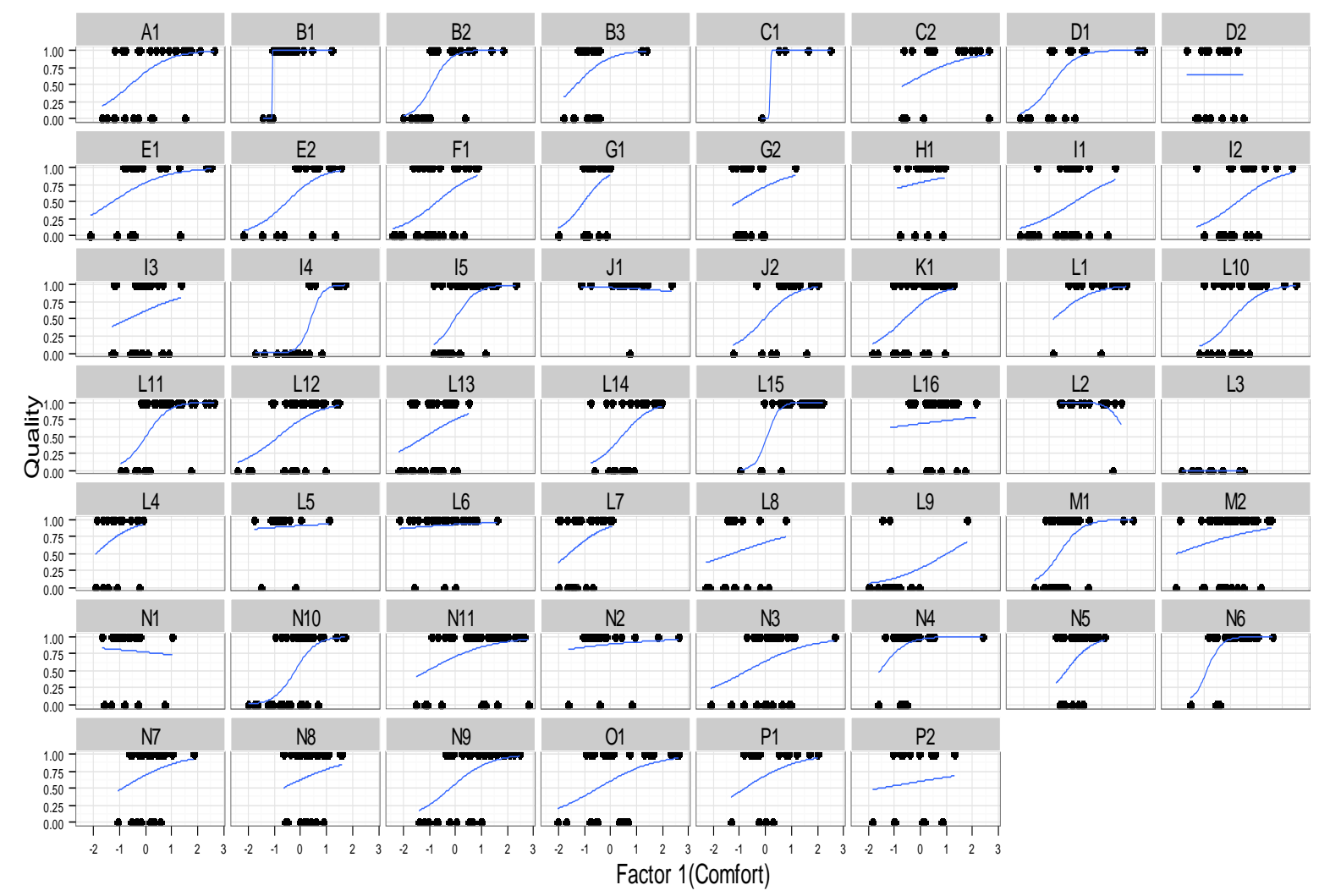

Figure 1. Relationship between quality and Comfort Factor for each bus line*

* Letter referred to operator and number referred to bus line

\subsection{Multilevel analysis}

To explain the overall quality considering only the effect of the bus line, first, a variance components model or "null model" have been estimated (Mod1), that is an LMLM without explanatory variables (Table 3 ). The odds that users value the quality of service as good or very good for an "average" line is estimated as $\exp (0.7752)=2.171$ with a probability of $2.1710 /(1+2.171)=0.6846$. In addition, we can conclude that there is significant variation in the commuters satisfaction with different bus lines because the p-value of Likelihood Ratio test $(\mathrm{LR}=38.385, \mathrm{df}=1, \mathrm{p}$-value $=0.000)$ for testing the null hypothesis, that $\sigma_{0}^{2}=0$, is less than 0.001 . The ICC $(\rho=0.1009)$ indicates that $10 \%$ of the variability in commuters is accounted for bus line. Also, we can examine estimates of conditional modes of the random effects caused by satisfaction with the use of different routes.

\begin{tabular}{|c|c|c|}
\hline & Mod1 & Mod2 \\
\hline \multicolumn{3}{|l|}{ Fixed-effects } \\
\hline & $0.775^{*}$ & $0.986^{*}$ \\
\hline
\end{tabular}




\begin{tabular}{|l|l|l|}
\hline Comfort Factor & \multicolumn{1}{l|}{$\begin{array}{l}\left(243^{*}\right. \\
(3.465)\end{array}$} \\
\hline Services supply Factor & & $\begin{array}{l}0.771^{*} \\
(3.323)\end{array}$ \\
\hline \multicolumn{2}{|l|}{} \\
\hline Random-effects (variance) & 0.3693 & 0.624 \\
\hline Model fit & & \\
\hline AIC & 1866.3 & 1552.1 \\
\hline BIC & 1876.9 & 1573.3 \\
\hline R2m & 0.000 & 0.353 \\
\hline R2c & 0.101 & 0.457 \\
\hline $\operatorname{logLik}$ & -931.1 & -772.0 \\
\hline
\end{tabular}

\section{Table 3. Multilevel models}

*Statistically significant, $\mathrm{p}<.01$. Entries show parameter estimates with odds-ratio in parentheses

Figure 2 (intercept-Mod1) displays the conditional modes of the random effects on bus lines, with $95 \%$ confidence intervals. In this Figure, we can see the estimated average satisfaction level of every bus route. We observed, for a confidence level of $95 \%$, that the effect of some of the lines was below or above the overall average of all surveys (vertical line zero).

We generally found that most travellers perceive quality similar to other users. However, users' opinions in lines L3, L9, I1, I4, F1 and N10 is significantly below average, which means that their perception of quality is lower than the average of the remaining lines. On the other hand, quality perceived by line L6 users is above average. L6 is a very direct route with a commercial speed similar to private vehicles because it goes along the highway without stops and in a bus-lane within the urban route. The L6 terminus is a very central point in Granada city where it is difficult to find free parking. 


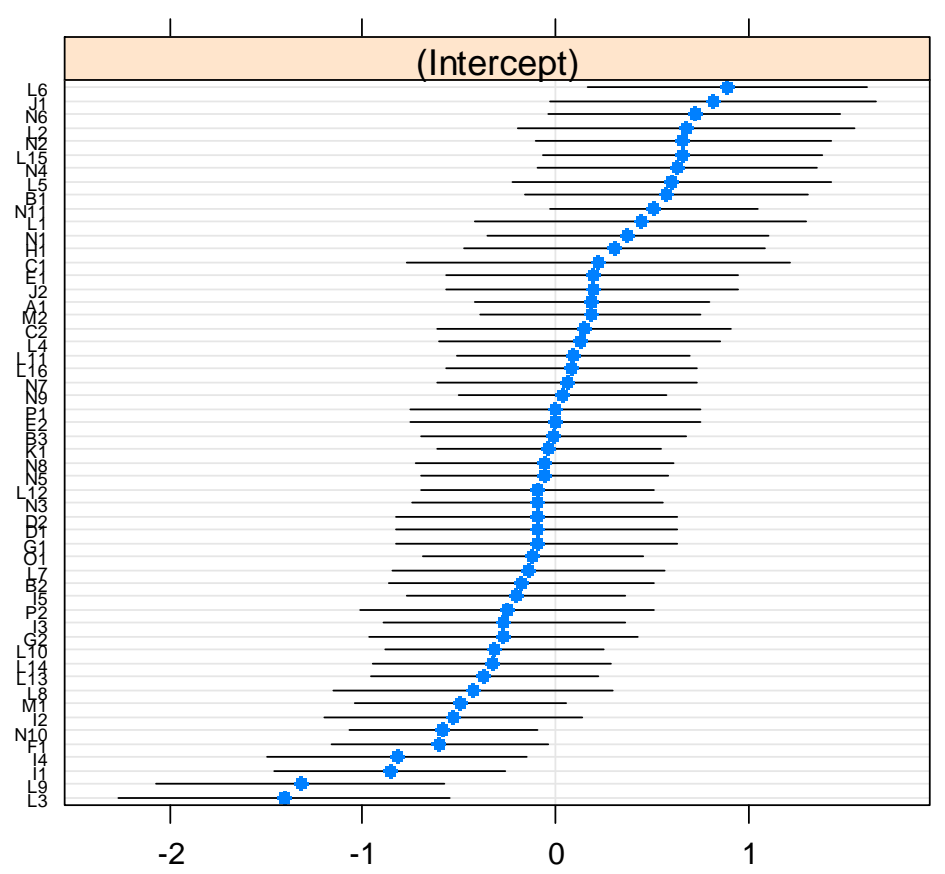

Figure 2. Conditional modes of the random effects

The explanatory variables Comfort Factor and Services supply Factor, which measure specific user satisfactions (Table 3, Mod2), were added to the Mod1. The effect that each variable produced on the response probability was given by the Odds Ratio (OR), which was calculated by $\exp (\beta)$. Table 3 , shows OR values for each variable. If OR is larger than 1 , the probability of giving a higher response modality increases as explanatory variable value increases. For instance, we would expect the odds that the service quality is rated as good or very good to increase when the Comfort Factor increases. In this way, for each 1-unit increase in Comfort Factor the probability of being satisfied with the service increases $246 \%$ $\left((3.465-1)^{*} 100\right)$.

\section{Discussion}

This research has identified factors which contribute to designing a model for evaluating public transport satisfaction. Previous empirical service satisfaction studies have proven to be a construct with multiple dimensions. The key dimensions regarding transport terms quoted are: reliability; responsibility; receptivity; staff behavior; attitudes and skills of those involved in provision; security; tangible; information; simplicity in information and capacity for problem solving; frequency; rates; comfort and cleanliness (Parasuraman et al., 1985; Bates et al., 2001; Hensher et al. 2003; Beirão and Cabral, 2007; Morfoulaki, Tyrinopoulos and Aifadopoulou, 2007; Fellesson and Friman, 2008). These quality components can be summarized into two categories: the technical dimension and the functional dimension (Grönroos, 1984). 
In the main component analysis, significant components emerge for the Comfort Factor and the Service supply Factor. The Comfort Factor, in which the variables that have a bigger relevance are: temperature, room/space, safety and punctuality, falls into the category of functional quality. This factor, determined by the feeling of comfort, obviously depends on the performance inside the vehicle as a result of both its own characteristics of habitability and the behavior of the driver during the journey. Punctuality may seem out of context but, as it was said earlier, we understand its relevance to this factor since delays in the schedule imply a longer stay inside the vehicle or at the bus stop and consequently greater exposure to the conditions of pleasure or displeasure with the service received.

The Service supply Factor is clearly subordinated to organization and management of metropolitan public transport and corresponds to the dimension of technical quality. Frequencies, schedules and the location of bus stops depend, first, on the concessional obligations of the operating company and, secondly, on the provisions of the transport authority that manages the system.

In addition, this paper has paid special attention to the effects that other unobserved variables, which affect each transport route, have on users' perception of quality of the public transport service. These unobserved variables show that the perception of the quality of service provided depends on the transport route used. Putting the focus on the various bus lines, these unobserved variables may be related to service management, vehicle commercial speed, type of journey, timeouts, etc. Those lines which have routes in high-capacity and speed roads obtained a higher satisfaction level than those where sections dominated by densely urbanized areas prevail. In the latter bus lines, the existence of a higher level of traffic jams, traffic lights, bus stops and some other adversities in circulation, bus speed limits cause dissonance between expected and received service.

We found that this was also due to the management of the various private operators. The Spanish concessional system restricts the capacity of transport authorities to intervene directly on how the service is transferred to public. Operators must comply with the established legal framework - especially, vehicle age range and accessibility to people with reduced mobility-, but they have full autonomy in order to organize their provision of public service contractual obligations.

\section{Conclusions}

This research aims to establish the determinants of satisfaction with public transport services to develop an interpretative model of perceived quality. In order to do so, various statistical and econometric techniques have been applied to data from the satisfaction survey conducted by Transport Consortium in the area of Granada among its users in 2013. The research shows that: 
The quality of service is a multidimensional concept where technical and functional aspects of the provision have considerable importance.

The analysis has revealed the existence of a stable framework for significant variables that explain the perception of quality.

The findings of the interpretive model of public transport service quality of this research are primarily based on unobservable effects that affect each bus line and other observable variables that can be grouped into two categories: Comfort Factor, and Service supply Factor. The Comfort Factor constitutes the functional dimension and the Service supply Factor provides the technical dimension for this model.

Users of different bus lines do not perceive the theme of quality. There are lines whose perceived quality is above or below the average perceived quality. This differential behavior may be due to different reasons, including the technical performance of the diverse operating companies, commercial speed, type of route, etc. Both operators and Public Administration will have to focus their attention on these lines in order to take economic policy measures to improve the lines with below standard compliance (Ongkittikul and Geerlings, 2006).

\section{Bibliography}

ASENSIO, J. and MATAS, A. (2008). Commuters' valuation of travel time variability. Transportation Research Part E 44, 1074-1085.

BARTHOLOMEW, D. J., STEELE, F., GALBRAITH, J., and MOUSTAKI, I. (2008). Analysis of multivariate social science data: CRC press.

BEIRÃO, G. and CABRAL, J.A. (2007). Understanding attitudes towards public transport and private car: A qualitative study. Transport Policy 14, 478-489.

BORRA, S. and CHIAVARINI, S. (2005). Multilevel models for perceived quality analysis: The case of local public transport of Rome. Statistica and Applicazioni, 3, 45-52.

DEL CASTILLO, J. and BENITEZ, F. (2013). Determining a public transport satisfaction index from user surveys. Transportmetrica A: Transport Science, 9(8), 713-741.

FELLESSON, M. and FRIMAN, M. (2008). Perceived Satisfaction with Public Transport Service in Nine European Cities. Journal of the Transportation Research Forum, Vol. 47, No 3 (Public Transit Special Issue 2008), 93-103.

FERRARI, P. A. and MANZI, G. (2014). Citizens evaluate public services: A critical overview of statistical methods for analysing user satisfaction. Journal of Economic Policy Reform, 17(3), 236-252.

FERRARI, P. A., PAGANI, L., and FIORIO, C. V. (2011). A two-step approach to analyze satisfaction data. Social Indicators Research, 104(3), 545-554.

FIORIO, C. V., FLORIO, M., and PERUCCA, G. (2013). User satisfaction and the organization of local public transport: Evidence from European cities. Transport Policy, 29, 209-218. 
GIFI, A. (1990). Nonlinear multivariate analysis. John Wiley and Sons. Chichester, England. GOLDSTEIN, H., BROWNE, W., and RASBASH, J. (2002). Partitioning variation in multilevel models. Understanding Statistics: Statistical Issues in Psychology, Education, and the Social Sciences, 1(4), 223-231.

GRÖNROOS, Ch. (1984). A Service Quality Model and its Marketing Implications. European Journal of Marketing, Vol. 18, $N^{\circ}$ 4, 36-44.

GRÖNROOS, Ch. (2006). On defining marketing: finding a new roadmap for marketing. Marketing Theory, 6, 395-417.

HENSHER, D. A., STOPHER, P. and BULLOCK, PH. (2003). Service quality-developing a service quality index in the provision of commercial bus contracts, Transportation Research Part A 37, 499-517.

JACKSON, D. A. (1993). Stopping rules in principal components analysis: a comparison of heuristical and statistical approaches. Ecology, 2204-2214.

JI, J. and GAO, X. (2010). Analysis of people's satisfaction with public transportation in Beijing. Habitat International, 34(4), 464-470.

JILKE, S. and VAN DE WALLE, S. (2013). Two track public services? Citizens' voice behaviour towards liberalized services in the EU15. Public Management Review, 15(4), 465-476.

KROES, E.P and SHELDON, R.J. (1988). Stated preference methods. Journal of Transport Economics and Policy, 11- 25.

LINTING, M., MEULMAN, J. J., GROENEN, P. J. and VAN DER KOOJJ, A. J. (2007). Nonlinear principal components analysis: introduction and application. Psychological methods, 12(3), 336.

LITMAN, T. (2003). Reinventing Transportation.Exploring the Paradigm Shift Needed to Reconcile Transportation and Sustainability Objectives. Victoria Transport Policy Institute, 27 June 2013. Electronic publication: http://www.vtpi.org/reinvent.pdf (may of 2014).

LIZÁRRAGA, C. (2006). Movilidad urbana sostenible: un reto para las ciudades del siglo XXI. Economía, Sociedad y Territorio, vol. VI, núm. 22, 283-321.

MEULMAN, J. and HEISER, W. J. (2001). SPSS Categories 13.0: SPSS Incorporated.

MIRALLES GUASCH, C. (2002). Ciudad y transporte: el binomio imperfecto, Ariel: Barcelona.

MORFOULAKI, M., TYRINOPOULOS, Y. and AIFADOPOULOU, G. (2007). Estimation of Satisfied Customers in Public Transport Systems: A New Methodological Approach. Journal of the Transportation Research Forum, Vol. 46, $N^{\circ}$ 1, 63-72.

NAKAGAWA, S. and SCHIELZETH, H. (2010). Repeatability for Gaussian and non Gaussian data: a practical guide for biologists. Biological Reviews, 85(4), 935-956.

NAKAGAWA, S. and SCHIELZETH, H. (2013). A general and simple method for obtaining R2 from generalized linear mixedeffects models. Methods in Ecology and Evolution, 4(2), 133-142.

DELL'OLIO, L., IBEAS, A. and CECÍN P. (2010). Modelling user perception of bus transit quality, Transport Policy 17, 388-397. 
DELL'OLIO, L., IBEAS, A. and CECÍN P. (2011). The quality of service desired by public transport users. Transport Policy 18, 217-227.

ONGKITTIKUL, S. and GEERLINGS, H. (2006). Opportunities for innovation in public transport: Effects of regulatory reforms on innovative capabilities. Transport Policy 13, 283-293.

DE OÑA, J., DE OÑA, R., EBOLI, L. and MAZZULLA, G. (2016). Index numbers for monitoring transit service quality. Transportation Research Part A, Vol. 84,18-30.

PARASURAMAN, A., ZEITHAML, V. A. and BERRY L.L. (1985). A Conceptual Model of Service Quality and Its Implications for Future Research. Journal of Marketing, Vol. 49, 41-50.

PAUllEY, N., BALCOMBE, R., MACKETT, R., TITHERIDGE, H., PRESTON, J., WARDMAN, M., SHIRES, J. A. and WHITE, P. (2006). The demand for public transport: The effects of fares, quality of service, income and car ownership. Transport Policy 13, 295-306.

ROMÁN, C., MARTÍN, J.C. and ESPINO, R. (2014). Using Stated Preferences to Analyze the Service Quality of Public Transport. International Journal of Sustainable Transportation 8:1, 28-46.

SNIJDERS, T. A. (2011). Multilevel analysis: Springer. 